\title{
Supernetwork to boost women in science
}

[BRUSSELS] Representatives of women in science groups across Europe and other bodies committed to improving the gender balance in scientific decision-making agreed last week to work together as a 'network of networks'.

A meeting in Brussels of 70 organizations making up the 'supernetwork' issued a joint statement of common goals and objectives. This described the under-representation of women in science as "a serious obstacle for the development of the sciences and for European society".

It called for all institutions that employ scientists to produce annual statistics on gender monitoring, and suggested increased lobbying and advocacy on the need for more women in science at national and European level.

Those attending the meeting - held under the auspices of the European Commission's research directorate, DGXII also proposed that the commission should use the network to document best practice in member states of the European Union. Fur-

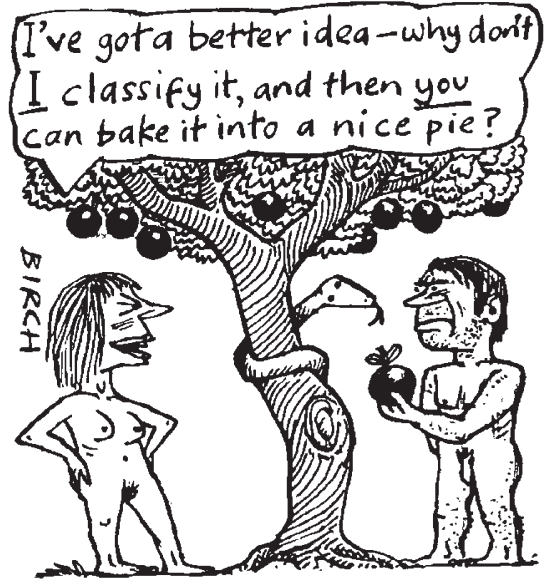

ther support for their joint activities will be sought from the commission.

Nicole Dewandre, of DGXII's Women and Science sector, says that the joint declaration is intended to establish the identity of the 'network of networks' before it starts "knocking on doors".

One of the goals of the Brussels meeting had been to bring those concerned about

\section{NASA to visit Mercury and dig into a comet}

[WASHINGTON] A return to the innermost planet Mercury and a mission to excavate material from a comet's nucleus were selected by the US space agency NASA last week as the next in its Discovery line of planetary missions.

The \$286 million Mercury Surface, Space Environment, Geochemistry and Ranging (Messenger) mission and the $\$ 240$ million comet impactor, called Deep Impact, beat three other finalists in the funding competition. Those were a sample return from the Martian moons Phobos and Deimos, a Jupiter orbiter, and a spacecraft to study the atmosphere of Venus.

A return visit to Mercury has been a perennial on the wish list for Solar System missions. Messenger will launch in 2004, 30 years after Mariner 10 made two quick flybys, the only reconnaissance of the planet to date. The spacecraft will arrive at Mercury in 2008, carrying seven instruments for imaging, spectrometry, laser altimetry, and measurements of the planet's magnetic field.

During its year in orbit, it will map the surface, including the hemisphere that Mariner missed. Messenger's principal investigator is Sean Solomon of the Carnegie Institution of Washington, and the spacecraft will be built and managed by the Johns Hopkins University Applied Physics Laboratory.

NASA's Jet Propulsion Laboratory will manage Deep Impact. This will create its own fireworks on 4 July 2005, Independence

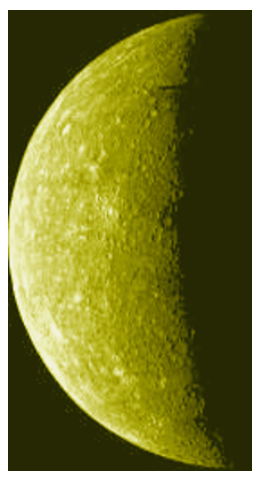

Day in the United States, when it smashes a 500-kilogram copper projectile into Comet $\mathrm{P} /$ Tempel 1 at a velocity of ten kilometres per second.

The impact will gouge out a crater at least 25 metres deep and 120 metres in diameter - deep enough to expose pristine material from Messenger will map Mercury's surface. inside the comet, hopes principal investigator

Michael A'Hearn of the University of Maryland. Cameras on the main spacecraft will image the evolution of the crater and the resulting plume in infrared and visible wavelengths.

A'Hearn was instrumental in organizing a ground-based campaign to observe the 1994 collision of comet Shoemaker-Levy 9 with Jupiter. He envisages a similar marshalling of professional and amateur telescopes to watch the artificial collision.

Deep Impact features another first for the Discovery programme - the offer of a 'piggyback' ride to other investigators. A'Hearn's team have an extra 10 kilograms of mass and 10 watts of power on the spacecraft, which it will make available for a technology experiment to be selected at a later date.

Tony Reichhardt gender issues in science into the commission's fifth Framework programme of research (FP5). "But we also wanted to ask what, as the commission, we could bring to them," says Dewandre.

The commission has undertaken to make "significant efforts" to increase women's participation in the union's research programmes. The overall objective is to achieve for women at least 40 per cent representation, on average, throughout FP5, including Marie Curie scholarships, advisory groups and assessment panels.

One hope for the meeting is that it will lead to an exchange of experience between the 'network of networks' and a separate network of government officials in member states involved in promoting women in scientific research. In the autumn both groups will consider a report on the challenges to women's participation in European research policy and put forward recommendations. This report is being produced by a group of experts set up last year by the commission. "There is a growth of awareness of the need for strategic action," says Dewandre.

The new network has been set up as part of the commission's efforts to establish links with Europe's existing networks of women scientists. The commission is especially keen to see more female applicants for 'expert positions' in advisory groups and assessment panels within FP5. The current figure stands at around 15 per cent.

The representatives of networks told the commission that it should consider paying higher salaries to researchers with families to support. They suggested that the age limit for fellowships should be relaxed to take into account academic years completed, rather than age - a move that would help women who had taken time out to raise a family.

But Achilleas Mitsos, director of DGXII, gave little ground when fielding such suggestions in an open session. This was "not the time to change council decisions," he said. "We should exert pressure, but this will come a little later."

Although some were "not optimistic" about Mitsos's reaction, all were positive about the outcome of the meeting and what could be gained by forming the network.

In a keynote speech, Catherine Jay Didion, executive director of the US Association for Women in Science, showed how the lobbying of politicians can be carried out effectively. The association has been largely responsible for the creation of the Congressmandated Commission on Women and Minorities in Science and Technology.

For some, the meeting itself was a revelation. "It has changed my life," says Sue Black of the British Computing Society. "I didn't know all these women were out there." NatashaLoder 